\title{
Distance Learning, a Case Study in Higher Education in Timisoara, Romania
}

\author{
Ileana Hauer ${ }^{\star}$
}

\begin{tabular}{l}
\hline \multicolumn{1}{c}{ A R T I C L E I N F O } \\
\hline Article history: \\
Accepted November 2020 \\
Available online December 2020 \\
\hline JEL Classification \\
M15 \\
Keywords: \\
Covid 19, Distance learning, \\
Blended learning, e-learning
\end{tabular}

1. Introduction

The 2019-2020 coronavirus pandemic has affected educational systems worldwide, leading to the widespread closures of schools and universities. According to UNESCO monitoring "in 8 April 2020, approximately 1.716 billion learners have been affected due to school closures in an attempt to stop spreading the COVID-19" (web1).

School closures impact not only students, teachers, and families, but have also economic and societal consequences. There is a list which is helping to understand why school closure affect to all of us:

- Pause of learning. Schools provide essential learning and when schools are closing children lost the opportunities for development. Parents are asked to help the learning of children, and this task can be difficult for many of them. This is especially common for parents with limited education and resources.

- Unequal access to digital learning platforms. In the absence of a computer, lack of access to technology or good internet connectivity are obstacles to continued learning, especially for students from disadvantaged families. This aspect was seen in Romania especially for children outside the cities where Internet access and having a computer were a real challenge.

According to a survey made by National Institute of Statistics (web2) from 2019, 75.7\% of the households in Romania had access to the home internet network, $61.8 \%$ of them concentrated in the urban area and $38.2 \%$ in the rural area. The Internet connection depends by the possibilities offered in the territorial plan by the providers of this service and by the financial availability that each household has.

- Problems in childcare. In the absence of other options, working parents often leave children alone when schools close and this can lead to risky behaviors.

- Lost jobs and economic penalties. In order to take care of their children the working parents are more likely to miss work when schools are closed. These situations are provoking wage loss in many instances and negatively impacting productivity.

- The last, but not more important: Social isolation: Schools are hubs of social activity and human interaction essential to learning and development. Psychotherapists warn that isolation further increases anxiety.

In response to school closures, UNESCO recommended the "use of distance learning programs and use platforms that schools and teachers can use to reach learners remotely and limit the disruption of education" (web3).

Keegan Desmond, the researcher who posed some of the foundational issues about distance education that are still outstanding, concluded that ",distance education is a distinct field of education, parallel to and a complement of conventional education" (1996). 
According to Mathew and Iloanya (2016) distance learning refers to "a method of instruction and acquisition of knowledge that is carried out in distance learning with the help of computer and technologies via internet". In the latest years many universities offer this kind of education, so the courses have become more varied and that the number of students are applying these programs is rising. According to Kör (2016) "distance learning offers equality of opportunity to individuals".

Greenberg defines distance learning as "a planned teaching/learning experience that uses a wide spectrum of technologies to reach learners at a distance and is designed to encourage learner interaction and certification of learning" (Greeberg, 1998). But not everyone can do distance learning. According to Wang (2008) distance learning requires "the student to have some specific characteristics like self-regulation and self-efficacy as well as to be motivated and able to work independently in order to successfully complete distance learning programs".

A distance learning program can be completely distance learning, or a combination of distance learning and traditional classroom instruction (called hybrid or blended). The term blended/hybrid learning is quite difficult to define since it is used in diverse ways. "Blended learning is a combination of traditional teaching methods of face to face and online approaches" (Littlejohn, Pegler, 2007).

In this paper we extend this definition. We see in blended learning a mixture of face-to-face learning and web-based technologies, both synchronous and asynchronous learnings.

\section{Literature review}

In the last two decades due to the new information and communication technologies, the educational system has changed considerably. The technologies has affect the course content permanently, and also the teaching methods should to be change. Almost all the teachers use the computer to present their courses.

Distance education technologies are separated into two modes of delivery: synchronous communication and asynchronous communication.

\subsection{Synchronous learning}

In synchronous learning mode, all attendees are "present" at the same time. It is required a timetable to be organized. In the past the synchronous mode of communication emerged with broadcast radio and interactive television. Nowadays the internet technology has allowed many form of distance learning. Some examples of synchronous technology are videoconferences, telephone, live streaming, or web-based VoIP. The videoconferences apps helps to organize meetings in distance learning courses and, usually, contain additional interaction tools such as text chat, polls, hand raising, emoticons etc.

According to Reviews.org (web4) the best videoconferencing software are:

- Zoom (best performance, allows 500 participants, 40 minutes limit on 100 participants for free).

- Skype (best free videoconferencing, four-hour time limit per call).

- Google Meet (best integration, integrates with Google Drive, allows 250 participants).

- Microsoft Teams (combines workplace chat, video meetings, file storage and application integration).

- Zoho Meeting (a versatile web conferencing tool for hosting meeting and webinars).

These tools also support asynchronous learning, the students are able to listen to the recordings of synchronous sessions. We concluded that synchronous learning is a type of two-way communication that occurs without a virtual time lag, enabling the attendees to respond in real time.

\subsection{Asynchronous learning}

In asynchronous learning, participants access course materials on their own schedules and they are not required to be together at the same time. Here we can exemplify with communication technologies (email, instant messaging, social media, etc.) and online collaborative spaces (LMS, Google Docs, Google Classroom, Dropbox, OneDrive, Office 365, etc.). We concluded that asynchronous learning is a type of twoway communication that occurs with a time lag, allowing participants to respond when they are ready to do it.

LMS is an abbreviation for Learning Management System, software system that allows the organization of online education through registration the training process, recording the test results, by going through the entire material educational to be transmitted.

A very well-known LMS is Moodle (Modular Object Oriented Dynamic Learning Environment), a free and open-source platform used to help teachers creating private websites with online courses and to coordinate students during the learning process.

The platform enables content management (laboratories, courses), ensures synchronized education (by chat rooms), and also asynchronized education (by forum, quiz, message) and, it can be used in managing the students that applied for the course. It is mandatory to have an internet connection. Also, in order to have a supportive learning course for online distance learners, the teachers must give a well-designed course and seminars materials. The platform's interface is very easy to be understand and used by students. The student's access is possible by an account created by teacher. The teacher can load resources as a file, create a link to a file or web site, insert a label with explications. Moodle allows, in addition to digital resource 
management, communication and interactivity, work cooperative on texts, evaluation of contributions and answers. A course can be associated with various activities, for example a quiz, which contains time settings, the attempts allowed, when the feedback will be given (figure 1).

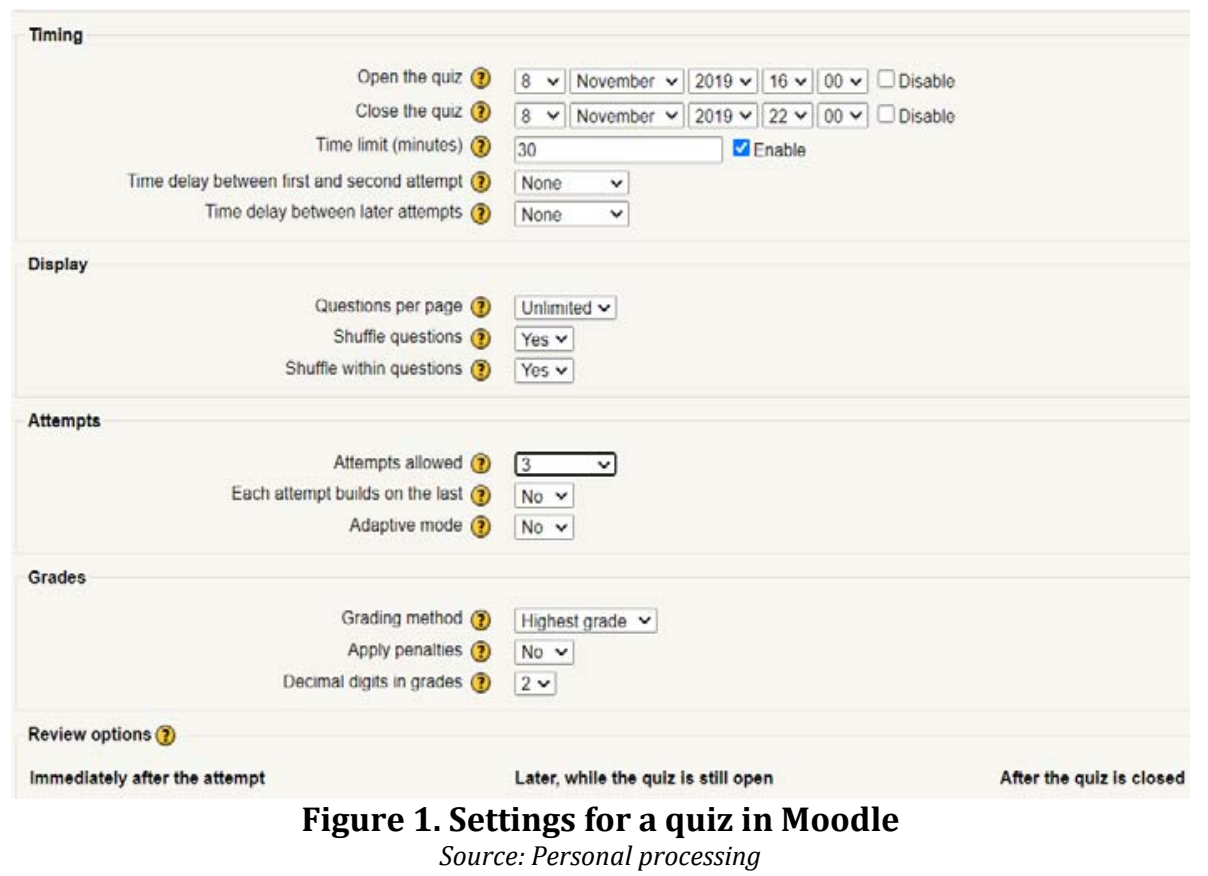

The figure 1 shows settings for a quiz, from 2019, with 30 minutes' time limit, 3 attempts allowed, and very important, not adaptive mode (the adaptive mode enables revealing the correct answers after closing the test). The scores can be given a) immediately after the attempt; b) later, while the quiz is still open; c) after the quiz is closed.

In order to have a supportive learning environment for online learners, the teachers need to give well-designed course materials and strong academic and tutorial support.

\section{Case study}

Our faculty, the Faculty of Economics and Business Administration, West University of Timisoara, has majors with face-to-face education and with distance education (Web6). The course of Visual Programming is compulsory for economic students in the fourth semester of the Economic Informatics major. The second semester began in February, with Visual Programming, C\#, and in an effort to limit transmission of the virus, has become a distance learning course. All courses/laboratories were taught using a videoconference app (Google Meet). All the materials for courses were posted on Moodle platform. The exams were both online, with quizzes from Moodle, and projects, sent by e-mail.

We asked students several questions, to find out whether the distance learning was indeed very beneficiary to them. Our students are from computer science, where computer practice is most necessary. Our succinct survey is summarized below:

a) The first question is about the development of theoretical courses, and student's answers are: $22 \%$ of students prefer face-to-face courses, $31 \%$ of students prefer videoconferences, $47 \%$ of students prefer blended courses (face-to-face and additional courses on Google Drive/Moodle) (figure 2).

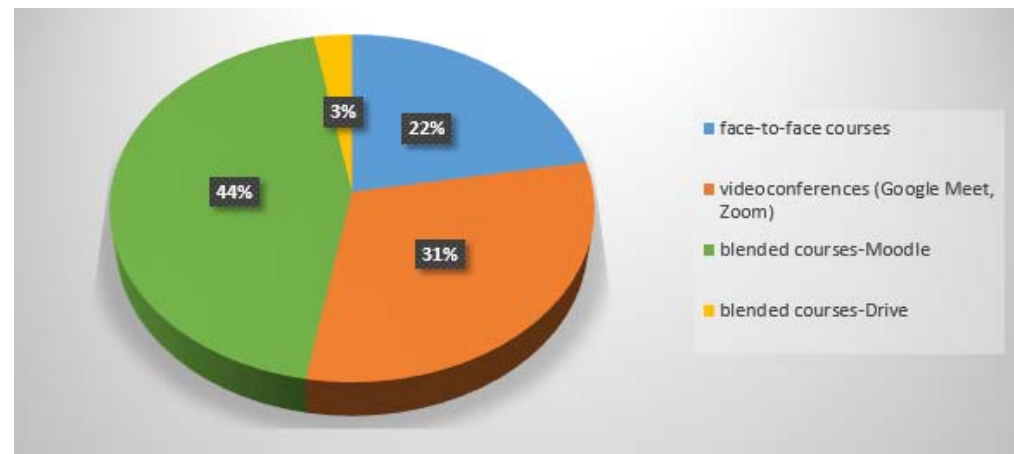

Figure 2. The student's opinion about courses

Source: Google forms. Personal processing 
The student's answers suggest that in the Internet era most of the students (78\%) prefer the courses supported by online platforms or remote, through videoconferencing.

b) The second question is about the development of laboratories, and student's answers are:

- $39 \%$ of students prefer face-to-face, as the interaction with colleagues and the teacher is more effective, but time is wasted writing the application on board

- $\quad 53 \%$ of students prefer a hybrid version, mixed between face-to-face and using of online platforms, access to application is fast and the teacher can help in case of errors

- $8 \%$ of students prefer the remote video conferencing system, the application is easier to follow.

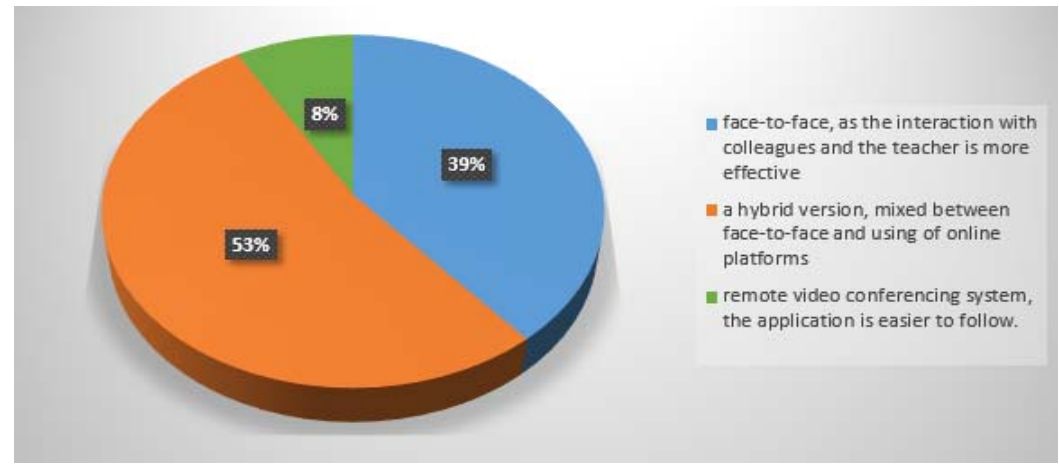

Figure 3. The student's opinion about laboratories

Source: Google forms. Personal processing

Due to the laboratories' complexity, most of students (92\%) prefer to have the teacher nearby in the laboratories.

c) The third question is about the volume of the work done in distance learning process. It is to be lower, equal, higher or much higher compared to the volume of work done in face-to-face education. The student's answers are:

- $16 \%$ of students believe that the work volume is smaller

- $25 \%$ of students believe that the work volume is even

- $53 \%$ of students believe that the work volume is bigger, as you must repeat the whole seminar at the end

- $3 \%$ of students believe that the work volume at some disciplines was higher, at other smaller

- $3 \%$ of students believe that the work volume was larger because it was more individual work, and often homework

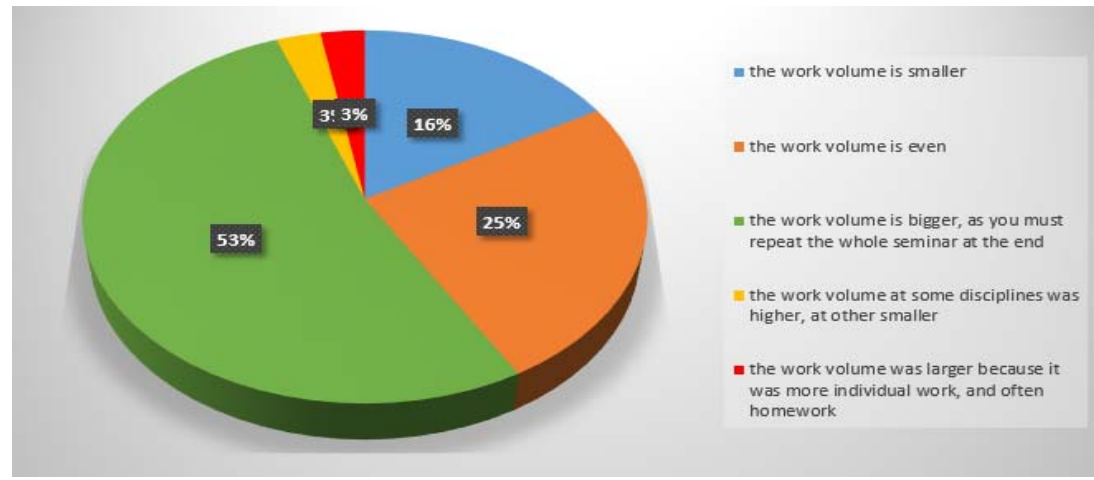

Figure 4. The student's opinion about the volume of work Source: Source: Google forms. Personal processing

The survey's analyze suggests that most of the students $(78 \%)$ think that the volume done for the understanding of the laboratory in the distance learning form is greater than/equal to previous volume (done in face to face form of education). This answer is in line with the Report on the perception by students from West University of Timisoara of the online education (In publishing manuscript, presented to the teachers of university, in videoconference, at April, 22, 2020). The report was made for covering the period 3.0413.04.2020 on a sample of 1417 students from West University of Timisoara. The Report also showed that the homework is denser in distance learning, and students spent too much time in front of the computer.

d) The fourth question is about preferences regarding taking the theoretical exam. The student's answers are:

- $78 \%$ of students prefer grid, online, from home 
- $6 \%$ of students prefer grid, online, in the classroom

- $8 \%$ of students prefer grid, in the classroom

- $8 \%$ of students prefer in the classroom, with subjects extensive

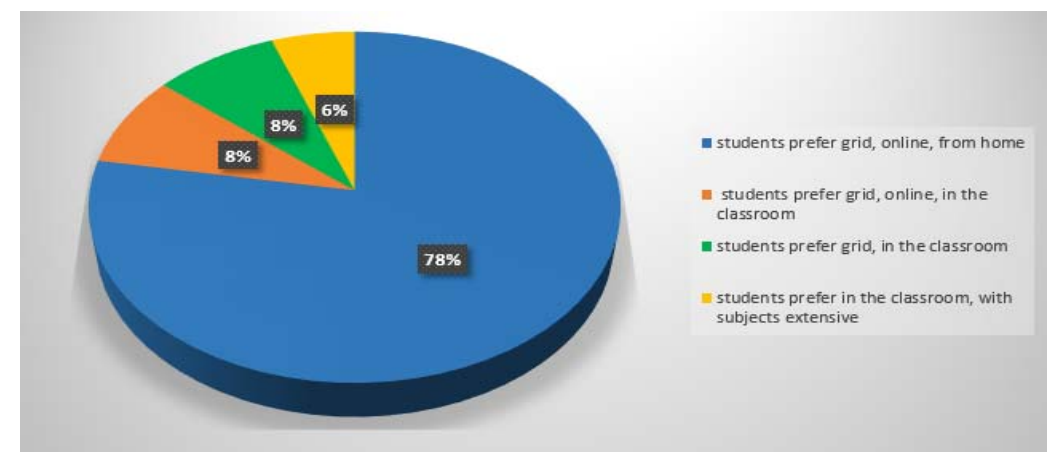

Figure 5. The student's opinion about taking the theoretical exam Source: Google forms. Personal processing

The answers suggest that mainly, the students prefer the comfort at home for the theoretical exam and choose the simplest form, the grid with answer templates.

e) The fifth question is about the preference with regards to taking the computer exam (this semester Microsoft Visual Studio, C\#). The students' answers are:

- $39 \%$ of students prefer the computer exam, online, from home, with time limit (sent by email, every student has a unique subject)

- $28 \%$ of students prefer the computer exam, in the classroom, the teacher can help

- $33 \%$ of students prefer in the form of a project, with examples from the application

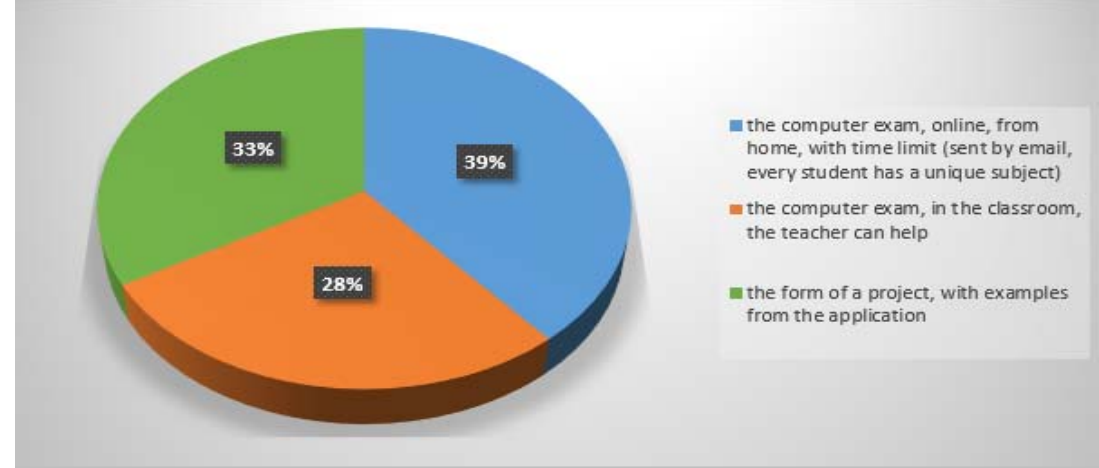

Figure 6. The student's opinion about taking the computer exam

Source: Google forms. Personal processing

The answers to the question about the computer exam are balanced, $1 / 3$ of students prefers working from home, $1 / 3$ of students prefers the classroom, where teacher can guide them, and $1 / 3$ of students prefers projects.

f) The sixth question analyzes which of the following aspects of distance education they consider to be disadvantages (several possible answers). The student's mixed choices are:

- 29 votes for too much time spend in front of computer

- 23 votes for the homework volume is larger in distance learning

- 16 votes for less social interaction

- 17 votes for chance of being distracted

- 15 votes for less interaction with teacher, essential for increasing confidence

- 14 votes for need of investment in a good computer, stable internet connection

- 5 votes for the possibility of cheating

- 2 votes for a few companies accept on line certifications

- 1 vote for some of the seminar's parts are more difficult to understand 


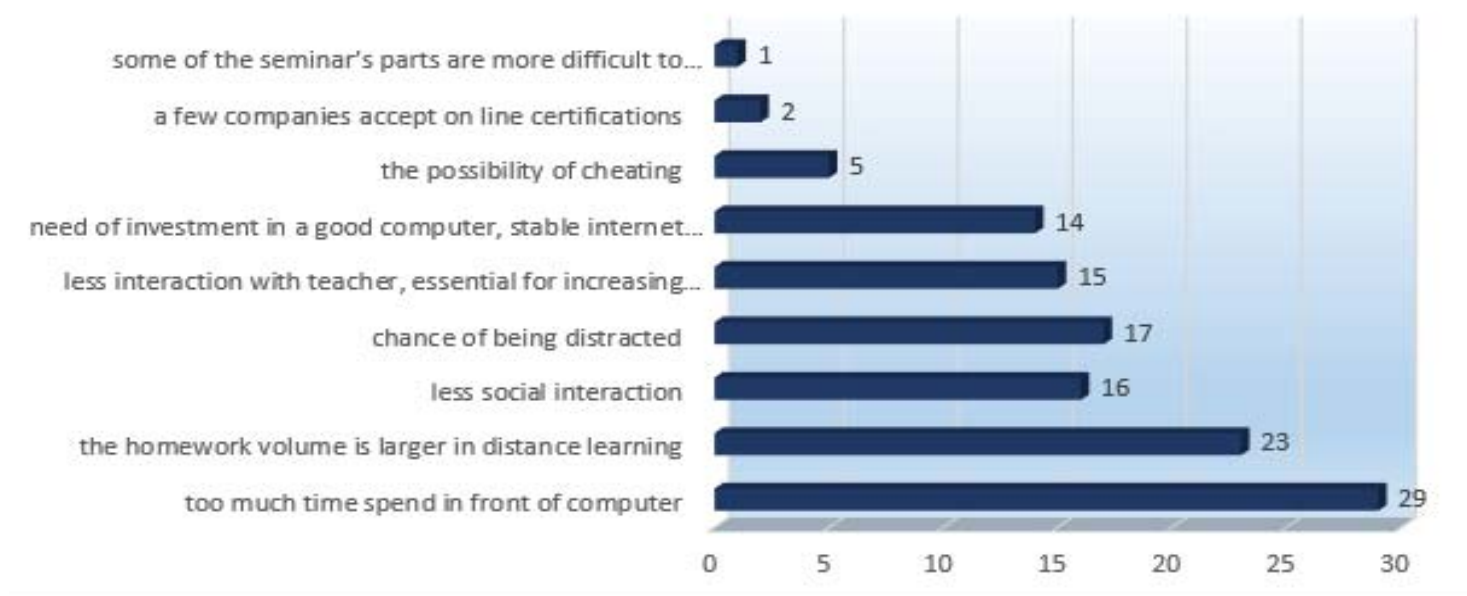

Figure 7. The student's opinion about pitfalls of distance education

Source: Google forms. Personal processing

The students' answers suggest that the biggest disadvantages of distance learning are spending too much time in front of the computer, more homework and less social interaction.

g) The seventh question analyzes which of the following aspects of distance education do they consider to be advantages? (Several possible answers). The student's mixed choices are:

- 31 votes for flexible period of learning

- 30 votes for less time for going to school

- 16 votes for learning at any age

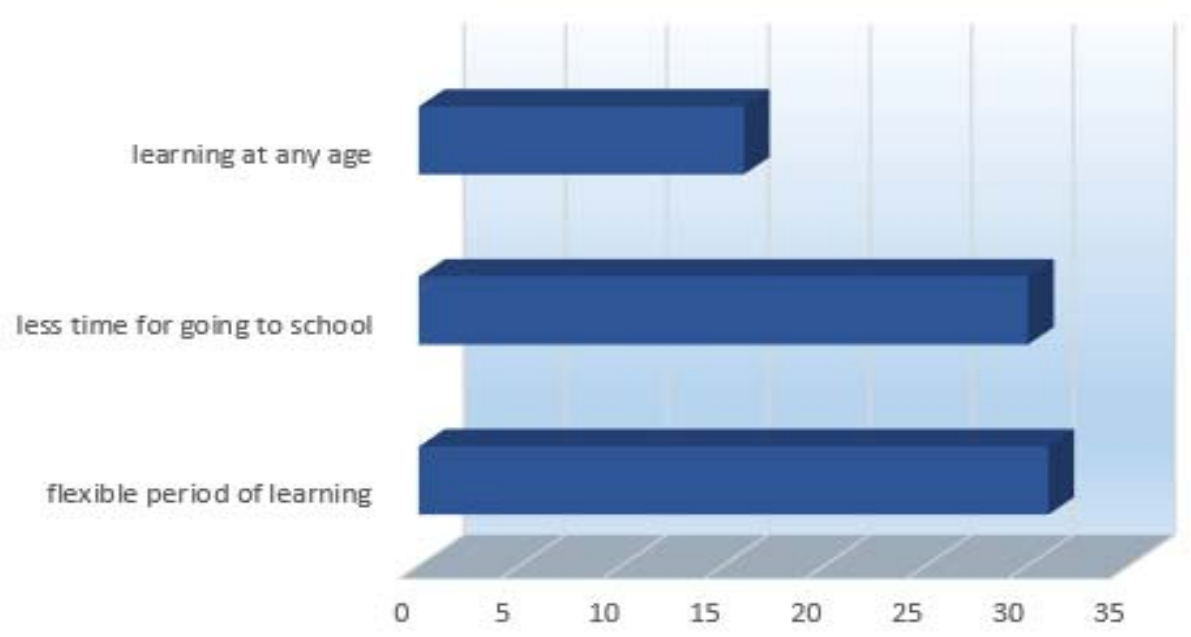

Figure 8. The student's opinion about strengths of distance education

Source: Google forms. Personal processing flexibility.

The student's answers suggest that the great advantages of distance learning are time and age

\section{Conclusions}

At first glance distance learning offers equality of opportunity to individuals. individuals who were unable to continue their undergraduate, graduate, or postgraduate education, for whatever reason, may now do so through distance learning. Our case study was looking for perceptions by students who, without asking, have gone from face-to-face education to distance learning. The main conclusions are:

- The current educational context has forced the university environment to adapt to new realities. The transfer of teaching activities in the online and remote environments occurred very quickly and forced the teachers and students to make sustained efforts to continue their work.

- The distance learning and online learning, are options for diversifying learning methods and enhanhancing the student's knowledge.

- Most of the students prefer distance theoretical courses, but they chose the part applied in the laboratory, where the teacher can help them. Even the laboratories are in videconference records, it is easier to be guided, than learn by yourself. 
- Most of the students claim that the volume submitted for the understanding of the laboratories is higher/or even in the distance learning form. Also the teachers tend to give more homework.

- Without the benefits of direct contact, the student needs to receive more feedback on the results of his activity. Simultaneously, it is expected that the teacher will give a more consistent individual feedback.

- Using LMS for teaching activities, course communication, quizes, is highly accepted by students, especially quizes from home.

- Some benefits of distance learning are a) flexibility, which enables students to learn from anyway, at anytime b) saving time and money. The students need to be responsible and motivated to work and learn independently.

- Some disadvantages of distance learning are: a) The quality of Internet connectivity, the price for a good computer, webcam, can be a big detriment to the effectiveness of distance learning. b) Also learning the technology for online/distance learning brings a new point of stress. Computer skills are much required in these forms of learning c) Not all the subjects are suitable for distance delivery d) Less social interection.

- If the pandemic persists for a long period, we might get used with distance learning, but the best solution is to alternate between face-to-face teaching (in case of meeting a small number of students, e.g. for laboratories) and distance instruction (in case of meeting many students). The blended learning is a better compromise solution for undergraduate students. The distance learning is more suitable for students at advanced and postgraduate courses.

\section{References}

1. Greenberg, G. (1998). Distance education technologies: Best practices for K 12 settings. IEEE Technology and Society Magazine, p.36-40.

2. Keegan, D. (1996) Foundations of distance education, New York, Routledge. Third Edition

3. Kör, H. Erbay, H., Demir, E., Akmese, Ö. F. (2016). A study on the factors affecting the academic performance of distance education students and formal students, Hit it. University Journal of Social Sciences Institute, 9(2), 1029-1050.

4. Littlejohn, A., Pegler, C. (2007). Preparing for blended e-Learning. UK: Routledge-Falmer.

5. Mathew, I.R., Iloanya, J.E. (2016) Open and Distance learning: benefits and challenges of technology usage for online teaching and learning in Africa. Published at Botho University, Botswana

6. Wang, Y., Peng, H., Huang, R., Hou, Y., \& Wang, J. (2008). Characteristics of distance learners: Research on relationships of learning motivation, learning strategy, self-efficacy, attribution and learning results. The Journal of Open and Distance Learning, 23(1), 17-28.

7. Web1 https://en.unesco.org/covid19 Accessed in 20.03.2020

8. Web2 https://insse.ro/cms/ro/tags/accesul-populatiei-la-tehnologia-informatiei-si-comunicatiilor Accessed in 3.04 .2020

9. Web3 https://en.wikipedia.org/wiki/Impact_of the_2019\%E2\%80\%9320_coronavirus_pandemic_on_education Accessed in 3.04.2020

10. Web4 https://www.reviews.org/internet-service/best-video-conferencing-apps/Accessed in 20.05 .2020

11. Web5 https://www.uvt.ro/ro/educatie/departamente-suport-educatie/decidfr/Accessed in 20.05.2020

12. Web6 https://feaa.uvt.ro/ro/Accessed in 20.05.2020 